\title{
Learning from accidents: analysis of multi-attribute events and implications to improve design and reduce human errors
}

\author{
R. Moura*, M. Beer, E. Patelli \& J. Lewis \\ Institute for Risk and Uncertainty, University of Liverpool, United Kingdom \\ F. Knoll \\ NCK Inc., Montreal, Canada
}

\begin{abstract}
High-technology accidents are likely to occur under a complex interaction of multiple active failures and latent conditions, and recent major accidents investigations are increasingly highlighting the role of human error or human-related factors as significant contributors. Latent conditions might have long incubation periods, which implies that a number of design failures may be embedded in systems until human errors trigger an accident sequence. Consequently, there is a need to scrutinise the relationship between enduring design deficiencies and human erroneous actions as a conceivable way to minimise accidents. This study will tackle this complex problem by applying an artificial neural network approach to a proprietary multiattribute accident dataset, in order to disclose multidimensional relationships between human errors and design failures. Clustering and data mining results are interpreted to offer further insight into the latent conditions embedded in design. Implications to support the development of design failure prevention schemes are then discussed.
\end{abstract}

\section{INTRODUCTION}

\subsection{Man-made disasters and the design role}

Human errors or human-related factors have been regarded as significant contributors or even the triggering element of recent major accidents, according to a number of technical investigations designated to determine the causes of these adverse events. Fukushima in Japan and Macondo in the Gulf of Mexico are examples, to name but a few, of catastrophic events deeply associated with direct human actions or flawed decision-making processes leading to devastating consequences. Kurokawa et al (2012), for example, concluded that the 2011 nuclear accident in Japan was a man-made disaster, a term coined almost 40 years ago by Turner (1978) to emphasise how information distortion generated by systems complexity can challenge risk prevention measures.

To describe the dynamics of accident causation, in his well-known "Swiss cheese" theory, Reason (1990) introduced the idea of a sequence of safety barriers (represented by cheese slices) with holes as an indication of flaws. Complex systems fail and accidents occur when a combination of synchronized flaws in these barriers take place or, better saying, as

*National Agency for Petroleum, Natural Gas and Biofuels (ANP), Brazil. a result of the alignment of the holes in the Swiss cheese slices. He also associated these flaws/holes to slips, lapses, mistakes, violations (or active failures) and latent conditions (Reason, 1997). Thus, it is widely accepted that high-technology accidents are likely to occur under a complex interaction of multiple active failures and latent conditions. These latent conditions might have long incubation periods, implying that a number of design failures may be embedded in systems until combined with human errors and exposed in an accident sequence.

Previous data analysis (Moura et al, 2015a) using a proprietary dataset structured to capture human, technology and organisational features from industrial accidents (Multi-attribute Technological Accidents Dataset - MATA-D), found that more than $60 \%$ of the events in the dataset featured some sort of design failure, which can be considered to be the most frequent single contributory factor (or latent condition) to major accidents. Consequently, the detection and correction of design gaps in earlier stages of the facilities' lifecycle, when the cost of corrections is significantly lower, would certainly reduce the likelihood of undesirable outcomes during the operational phase. However, traditional hazard identification methods used in design such as Fault-trees or FMECAs (Failure Mode, Effects, and Criticality Analysis), in spite of being very successful in disclosing undesirable conditions (Vesely et al, 1981), 
have some limitations that might be preventing the recognition of multidimensional factors leading to a critical accident. These limitations can arise from their structure (one rigid/hierarchical, the other dependent on the accurate prediction of all failure modes) or from difficulties in encompassing simultaneous failures involving humans and organisations. In fact, industrial accidents investigations attest that seemingly autonomous features typically found in industrial environments can be combined and synchronised in an apparently unpredictable fashion to produce critical accidents.

This exposes the need for a novel method focused on the examination of specific interactions between latent design deficiencies and human erroneous actions, assuming that the identification of common patterns from real-world accidents can provide some guidance to design failure prevention schemes. Limitations in dealing with complex data will be overcome by the application of the self-organising maps (SOM) algorithm developed by Kohonen (2001) in a major-accidents dataset, followed by the detailed interpretation of the output with regard to design failures.

\section{BACKGROUND}

\subsection{The Multi-Attribute Technological Accidents Dataset (MATA-D)}

In order to capture human, technology and organisational features from industrial accidents, the authors developed a comprehensive dataset by collecting data from insurance companies, regulators, industry and official commissions designated to investigate major accidents. The proposed dataset structure followed Hollnagel's (1998) Cognitive Reliability and Error Analysis Method (CREAM) taxonomy, and was used in this work to identify and classify events from different industrial domains under a common framework. As major accidents can be considered to be rare events, having the possibility to merge a number of significant events generated from seemingly dissimilar industrial segments, such as aviation and chemicals factories, would build-up sufficient data to allow statistical analysis and disclose common associations. This novel approach might prove to be a powerful alternative to understand how latent conditions embedded in design are interacting with human errors to generate or contribute to major accidents.

In summary, features related to (i) human erroneous actions (e.g. timing, omission, wrong direction, wrong object, wrong sequence); (ii) human cognitive functions (e.g. observation missed, wrong identification, decision error, wrong reasoning, incorrect pre- diction, inadequate plan, priority error); (iii) temporary person-related functions (e.g. fear, fatigue, distraction); (iv) permanent person-related functions (e.g. functional impairment); (v) technology (e.g. equipment failure, inadequate procedure, software fault); and (vi) organisation (e.g. communication, maintenance failure, quality control, design failure, inadequate task allocation, training, working conditions) are extracted from the accident reports and organised in a matrix in order to allow numerical analysis (using binary tables containing the presence or absence of attributes). Each accident can simultaneously contain up to 53 of these human, technology and organisational factors. Detailed evaluations and further interpretation are also possible, by using the brief descriptions containing the hot spots of each one of the identified factors, as interpreted from the accident reports. Moura et al (2015a) presented a full account of the proposed classification scheme and a detailed example of an accident dissection.

Currently, the dataset contains 216 accidents from several industrial domains (e.g. refining, upstream (oil \& gas), terminals and distribution, petrochemicals, construction, metallurgy, nuclear and gas processing and chemicals).

\section{DATASET ANALYSIS METHOD}

\subsection{Clustering and data mining using self- organisation}

Aiming at the identification of groups of major industrial accidents sharing common features, an unsupervised training neural network technique named Self-organising Maps (Kohonen, 2001), was applied to the MATA-D dataset. The resulting selforganisation summarises the multidimensional data (a 216 x 53 Matrix, in the current study) in a twodimensional topographic map (Figure 1), where accidents were mutually attracted by a similarity criteria and thus adjacently grouped. 2-D SOM maps were created with Viscovery ${ }^{\circledR}$ SOMine expert version.

Figure 1 clearly shows five distinct regions as a result of the application of the SOM algorithm, meaning that similar accidents were connected by five different basic settings. A comprehensive description of the SOM algorithm and the main features of the resulting five clusters were extensively discussed by Moura et al (2015b), and this work will provide a step forward by focusing on the identification and interpretation of the features specifically related to the Design Failure factor, which highest incidences were observed in Clusters 1 and 4, respectively. Results will reveal gaps and provide further insight into the design weaknesses which may be contributing to the perpetuation of human errors. 


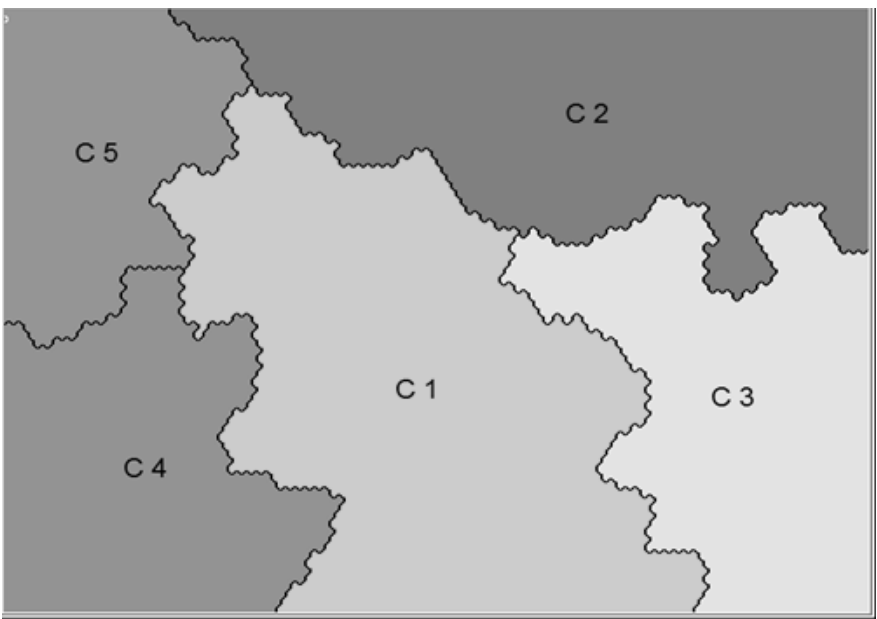

Figure 1. SOM Clustering for MATA-D, after Moura et al (2015b)

\section{RESULTS}

\subsection{Design Failure Clustering results}

The Design Failure factor highest incidences were shown in Clusters 1 and 4, with $86.0 \%$ and $83.3 \%$, respectively. Therefore, once the self-organising maps algorithm had been used to highlight these two groups as the most important from a design perspective, further analysis on the individual features' SOM maps will be conducted in order to disclose relevant associations. Table 1 presents the overall importance of each human (from Wrong Time to Cognitive Bias), technology (from Equipment Failure to Mislabelling) and Organizational (from Communication Failure to Inadequate Working Hours) feature for the full dataset, compared to the results of the SOM algorithm for clusters 1 and 4 . For instance, it can be seen that the Design Failure factor frequency has shown an increase of $23.5 \%$ for cluster 1 and of $20.8 \%$ in cluster 4 , above the overall incidence of $62.5 \%$.

Table 1. MATA-D Overall Frequencies vs. SOM clusters $1 \& 4$ frequencies

\begin{tabular}{lccccc}
\hline Factor & Overall & Cluster 1 & $\begin{array}{c}\text { Var. } \\
(\mathrm{C} 1-\mathrm{T})\end{array}$ & $\begin{array}{c}\text { Cluster } \\
4\end{array}$ & $\begin{array}{c}\text { Var. } \\
(\mathrm{C} 4-\mathrm{T})\end{array}$ \\
\hline Wrong Time & $14.8 \%$ & $\mathbf{3 8 . 0} \%$ & $\mathbf{2 3 . 2 \%}$ & $2.8 \%$ & $-12.0 \%$ \\
Wrong Type & $13.0 \%$ & $\mathbf{2 6 . 0 \%}$ & $\mathbf{1 3 . 0} \%$ & $8.3 \%$ & $-4.6 \%$ \\
Wrong Object & $2.3 \%$ & $2.0 \%$ & $-0.3 \%$ & $5.6 \%$ & $3.2 \%$ \\
Wrong Place & $26.9 \%$ & $6.0 \%$ & $-20.9 \%$ & $\mathbf{5 2 . 8 \%}$ & $\mathbf{2 5 . 9 \%}$ \\
\hline Obs. Missed & $15.3 \%$ & $\mathbf{2 6 . 0 \%}$ & $\mathbf{1 0 . 7 \%}$ & $0.0 \%$ & $-15.3 \%$ \\
False Observ. & $2.3 \%$ & $0.0 \%$ & $-2.3 \%$ & $2.8 \%$ & $0.5 \%$ \\
Wrong Id. & $2.8 \%$ & $2.0 \%$ & $-0.8 \%$ & $5.6 \%$ & $2.8 \%$ \\
\hline Diagnosis & $13.0 \%$ & $16.0 \%$ & $3.0 \%$ & $11.1 \%$ & $-1.9 \%$ \\
Reasoning & $12.0 \%$ & $20.0 \%$ & $8.0 \%$ & $\mathbf{2 7 . 8 \%}$ & $\mathbf{1 5 . 7 \%}$ \\
Decision error & $8.8 \%$ & $12.0 \%$ & $3.2 \%$ & $2.8 \%$ & $-6.0 \%$ \\
Interp. Delay & $5.1 \%$ & $8.0 \%$ & $2.9 \%$ & $5.6 \%$ & $0.5 \%$ \\
Incor. Predict. & $3.7 \%$ & $6.0 \%$ & $2.3 \%$ & $11.1 \%$ & $7.4 \%$ \\
\hline Inad. Plan & $9.7 \%$ & $16.0 \%$ & $6.3 \%$ & $2.8 \%$ & $-6.9 \%$ \\
Priority error & $6.9 \%$ & $14.0 \%$ & $7.1 \%$ & $2.8 \%$ & $-4.2 \%$ \\
\hline
\end{tabular}

\begin{tabular}{lccccc}
\hline Memory fail & $0.9 \%$ & $0.0 \%$ & $-0.9 \%$ & $0.0 \%$ & $-0.9 \%$ \\
Fear & $2.3 \%$ & $2.0 \%$ & $-0.3 \%$ & $0.0 \%$ & $-2.3 \%$ \\
Distraction & $6.5 \%$ & $4.0 \%$ & $-2.5 \%$ & $2.8 \%$ & $-3.7 \%$ \\
Fatigue & $3.2 \%$ & $4.0 \%$ & $0.8 \%$ & $2.8 \%$ & $-0.5 \%$ \\
Perf. var. & $1.4 \%$ & $0.0 \%$ & $-1.4 \%$ & $0.0 \%$ & $-1.4 \%$ \\
Inattention & $2.3 \%$ & $2.0 \%$ & $-0.3 \%$ & $0.0 \%$ & $-2.3 \%$ \\
Physio. stress & $0.9 \%$ & $0.0 \%$ & $-0.9 \%$ & $2.8 \%$ & $1.9 \%$ \\
Psycho. stress & $3.2 \%$ & $2.0 \%$ & $-1.2 \%$ & $5.6 \%$ & $2.3 \%$ \\
\hline Func. Impair. & $0.5 \%$ & $2.0 \%$ & $1.5 \%$ & $0.0 \%$ & $-0.5 \%$ \\
Cognitive styl & $0.0 \%$ & $0.0 \%$ & $0.0 \%$ & $0.0 \%$ & $0.0 \%$ \\
Cognitive bias & $6.9 \%$ & $10.0 \%$ & $3.1 \%$ & $8.3 \%$ & $1.4 \%$ \\
\hline Equip failure & $57.9 \%$ & $\mathbf{8 2 . 0 \%}$ & $\mathbf{2 4 . 1 \%}$ & $61.1 \%$ & $3.2 \%$ \\
Software fault & $2.8 \%$ & $0.0 \%$ & $-2.8 \%$ & $5.6 \%$ & $2.8 \%$ \\
\hline Inadeq. proc. & $43.1 \%$ & $44.0 \%$ & $0.9 \%$ & $\mathbf{7 7 . 8 \%}$ & $\mathbf{3 4 . 7 \%}$ \\
\hline Access limits & $1.4 \%$ & $0.0 \%$ & $-1.4 \%$ & $2.8 \%$ & $1.4 \%$ \\
Ambig. Info. & $2.8 \%$ & $6.0 \%$ & $3.2 \%$ & $2.8 \%$ & $0.0 \%$ \\
\hline Incomp. info. & $13.9 \%$ & $20.0 \%$ & $6.1 \%$ & $16.7 \%$ & $2.8 \%$ \\
Access probs & $1.4 \%$ & $2.0 \%$ & $0.6 \%$ & $5.6 \%$ & $4.2 \%$ \\
Mislabelling & $1.4 \%$ & $0.0 \%$ & $-1.4 \%$ & $2.8 \%$ & $1.4 \%$ \\
\hline Communic. & $11.1 \%$ & $\mathbf{2 6 . 0 \%}$ & $\mathbf{1 4 . 9 \%}$ & $5.6 \%$ & $-5.6 \%$ \\
Missing info. & $19.0 \%$ & $20.0 \%$ & $1.0 \%$ & $\mathbf{5 8 . 3 \%}$ & $\mathbf{3 9 . 4 \%}$ \\
\hline Maintenance & $34.7 \%$ & $42.0 \%$ & $7.3 \%$ & $\mathbf{8 3 . 3 \%}$ & $\mathbf{4 8 . 6 \%}$ \\
Quality Ctrl. & $57.4 \%$ & $\mathbf{8 2 . 0 \%}$ & $\mathbf{2 4 . 6 \%}$ & $\mathbf{9 7 . 2 \%}$ & $\mathbf{3 9 . 8 \%}$ \\
Management & $10.2 \%$ & $18.0 \%$ & $7.8 \%$ & $19.4 \%$ & $9.3 \%$ \\
Design & $\mathbf{6 2 . 5 \%}$ & $\mathbf{8 6 . 0 \%}$ & $\mathbf{2 3 . 5 \%}$ & $\mathbf{8 3 . 3 \%}$ & $\mathbf{2 0 . 8 \%}$ \\
Task alloc. & $56.5 \%$ & $62.0 \%$ & $5.5 \%$ & $\mathbf{9 7 . 2 \%}$ & $\mathbf{4 0 . 7 \%}$ \\
Social press. & $6.9 \%$ & $0.0 \%$ & $-6.9 \%$ & $\mathbf{2 2 . 2 \%}$ & $\mathbf{1 5 . 3 \%}$ \\
\hline Skills & $36.6 \%$ & $\mathbf{7 2 . 0 \%}$ & $\mathbf{3 5 . 4 \%}$ & $36.1 \%$ & $-0.5 \%$ \\
Knowledge & $33.3 \%$ & $\mathbf{6 0 . 0 \%}$ & $\mathbf{2 6 . 7 \%}$ & $\mathbf{6 3 . 9 \%}$ & $\mathbf{3 0 . 6 \%}$ \\
\hline Temperature & $1.4 \%$ & $2.0 \%$ & $0.6 \%$ & $0.0 \%$ & $-1.4 \%$ \\
Sound & $0.0 \%$ & $0.0 \%$ & $0.0 \%$ & $0.0 \%$ & $0.0 \%$ \\
Humidity & $0.0 \%$ & $0.0 \%$ & $0.0 \%$ & $0.0 \%$ & $0.0 \%$ \\
Illumination & $0.9 \%$ & $0.0 \%$ & $-0.9 \%$ & $5.6 \%$ & $4.6 \%$ \\
Other & $0.0 \%$ & $0.0 \%$ & $0.0 \%$ & $0.0 \%$ & $0.0 \%$ \\
Ambient cond & $7.4 \%$ & $4.0 \%$ & $-3.4 \%$ & $5.6 \%$ & $-1.9 \%$ \\
\hline Demand & $5.6 \%$ & $2.0 \%$ & $-3.6 \%$ & $5.6 \%$ & $0.0 \%$ \\
Tayout & $2.8 \%$ & $2.0 \%$ & $-0.8 \%$ & $2.8 \%$ & $0.0 \%$ \\
\hline & & & & & \\
Woaming hrs & $4.2 \%$ & $2.0 \%$ & $-2.2 \%$ & $5.6 \%$ & $1.4 \%$ \\
\hline
\end{tabular}

Factors which presented a positive variation of more than $10 \%$ in relation to the overall frequency are in bold. These figures highlight which human, technology and organisational features were most attracted to a specific cluster at the topological map depicted in Figure 1, clearly differentiating the significant features of accidents particularly associated with design failures. Three factors have shown a substantial increase in both analysed clusters: Design Failure, Inadequate Quality Control and Insufficient Knowledge. Another important finding observed from the enhanced analysis of the resulting clustering is that $58 \%$ of the accidents in cluster one shared a simultaneous trio of factors in the origin of the events: Design Failure, Inadequate Quality Control and Equipment Failure, while $81 \%$ of the Cluster 4's events contained in their core the Design Failure, Inadequate Quality Control and Inadequate Task Allocation factors. These numbers indicate a well- 
defined path for further investigation, as the genesis of major accidents involving design failures appears to be grounded on a very limited amount of factors.

Cluster 1 accidents, which were deeply associated with the Design Failure, Inadequate Quality Control and Equipment Failure factors, were largely accompanied by two very specific human erroneous actions, Wrong Time and Wrong Type. In this grouping, these human errors were uniformly connected with all three cognitive levels (Observation, Interpretation and Planning), but with an observable greater tie between the Wrong Time and Observation Missed factors, as exemplified in Figures 2 and 3.

The SOM maps for individual features (Figures 2 to 6) are binary, meaning that the dark grey zone is where the analysed item was absent, while the light grey represents the regions were the feature was observed.

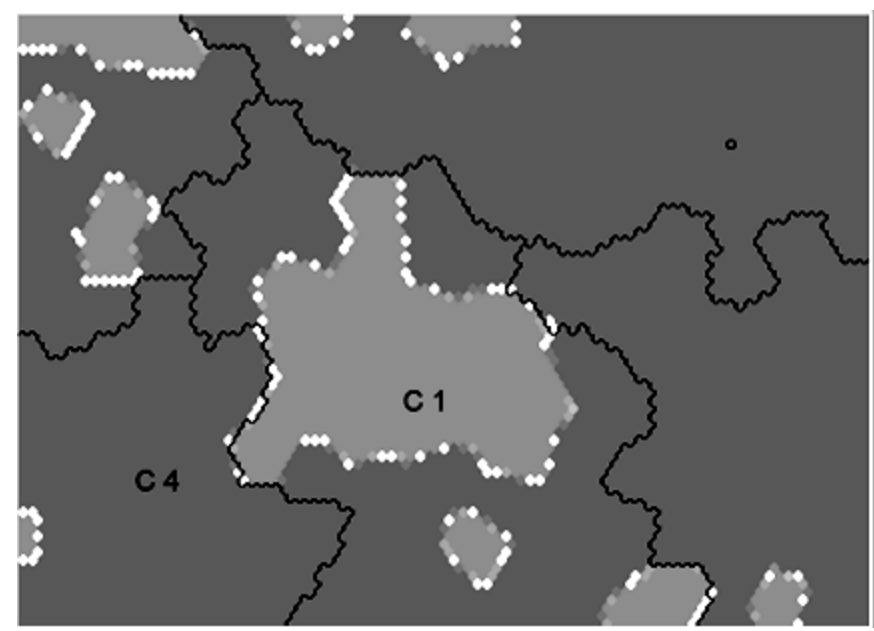

Figure 2. Wrong Time SOM

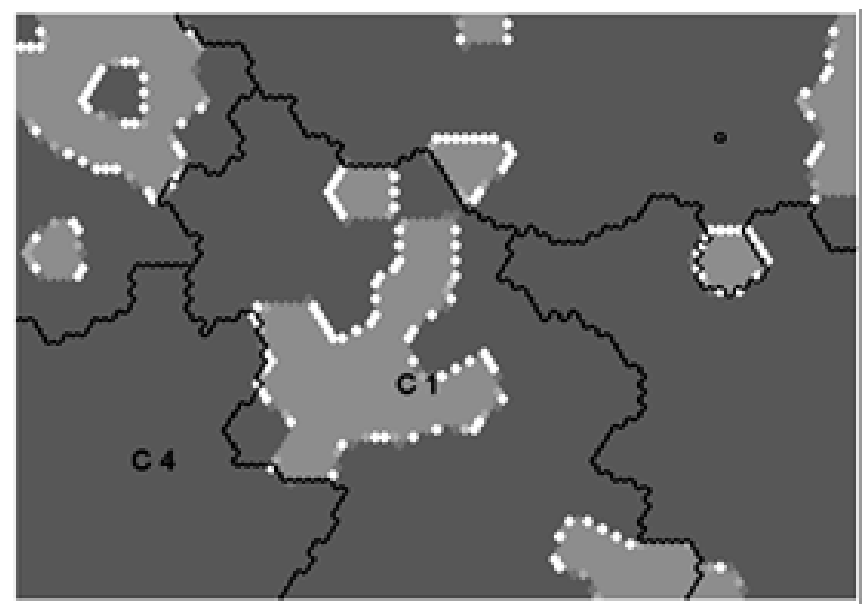

Figure 3. Observation missed SOM

Further analysis of the Wrong Time SOM also allows identifying that in the scarce cases where Design Failure did not seem to contribute to the accidents, an Insufficient Skills issue (i.e. lack of practical experience or equipment mishandling) was manifested and joined the Inadequate Quality Control and Equipment Failure factors to contribute to the undesirable outcome. When Inadequate Quality Control or Equipment Failure did not appear to directly contribute to the accident (highlighted regions on Figure 4), the Wrong Time feature was equally represented, but combined with the Insufficient Knowledge factor (e.g. lack of understanding of the situation).

Table 2. Cluster 1 accident examples

\begin{tabular}{|c|c|c|c|}
\hline Design Failure & Observation & Interpretation / Planning & Erroneous action \\
\hline $\begin{array}{l}\text { Safety Valve was not de- } \\
\text { signed to be next to the } \\
\text { protected pump, so re- } \\
\text { moval identification was } \\
\text { not visually possible from } \\
\text { pump room. }\end{array}$ & $\begin{array}{l}\text { Operator overlooked } \\
\text { cue/signal, by not realis- } \\
\text { ing that the safety valve } \\
\text { was out for maintenance } \\
\text { when inspecting pump. }\end{array}$ & $\begin{array}{l}\text { Faulty diagnosis about pump opera- } \\
\text { tional state (valve had been removed } \\
\text { for maintenance but the crew started } \\
\text { the pump after visual inspection). }\end{array}$ & $\begin{array}{l}\text { Timing, too early: operator } \\
\text { started pump before it has been } \\
\text { cleared by maintenance. }\end{array}$ \\
\hline $\begin{array}{l}\text { Due to design and manu- } \\
\text { facture failure, check } \\
\text { valve broke (internal pin) } \\
\text { upon pneumatic closure } \\
\text { and allowed flux. }\end{array}$ & $\begin{array}{l}\text { Valve position was not } \\
\text { checked after system trip. } \\
\text { Gas compression system } \\
\text { flow variations (immedi- } \\
\text { ate increase followed by } \\
\text { gradual drop) were not } \\
\text { seen by operator during } \\
\text { restart attempts. }\end{array}$ & $\begin{array}{l}\text { Wrong Priorities: without a clear in- } \\
\text { dication of a serious problem (no de- } \\
\text { tection alarm), foreman focused on } \\
\text { restarting the system as soon as pos- } \\
\text { sible to reduce lost resources (flaring } \\
\text { of uncompressed gases), after a pow- } \\
\text { er loss. }\end{array}$ & $\begin{array}{l}\text { Timing, too early: Operator } \\
\text { tried to restart gas compression } \\
\text { system before full electrical } \\
\text { power had been restored, caus- } \\
\text { ing the system to trip (and the } \\
\text { valves to slam shut) many times. }\end{array}$ \\
\hline $\begin{array}{l}\text { Pump design allowed up- } \\
\text { side-down plate fitting. } \\
\text { Critical alarm was not au- } \\
\text { dible (only visual). }\end{array}$ & $\begin{array}{c}\text { Plant alarm signals were } \\
\text { overlooked. }\end{array}$ & $\begin{array}{l}\text { Indirect indications of pump stop- } \\
\text { page appeared to be misinterpreted } \\
\text { by process operators. }\end{array}$ & $\begin{array}{l}\text { Wrong direction/type: Clamping } \\
\text { plate was fitted upside down } \\
\text { thus fixing bolds were misa- } \\
\text { ligned. }\end{array}$ \\
\hline
\end{tabular}

Table 2 highlights some MATA-D extracts of cluster 1-type accidents, focusing on the interaction between design failures; observation, interpretation and plan- ning cognitive functions; and Wrong Time/Wrong Type erroneous actions. 


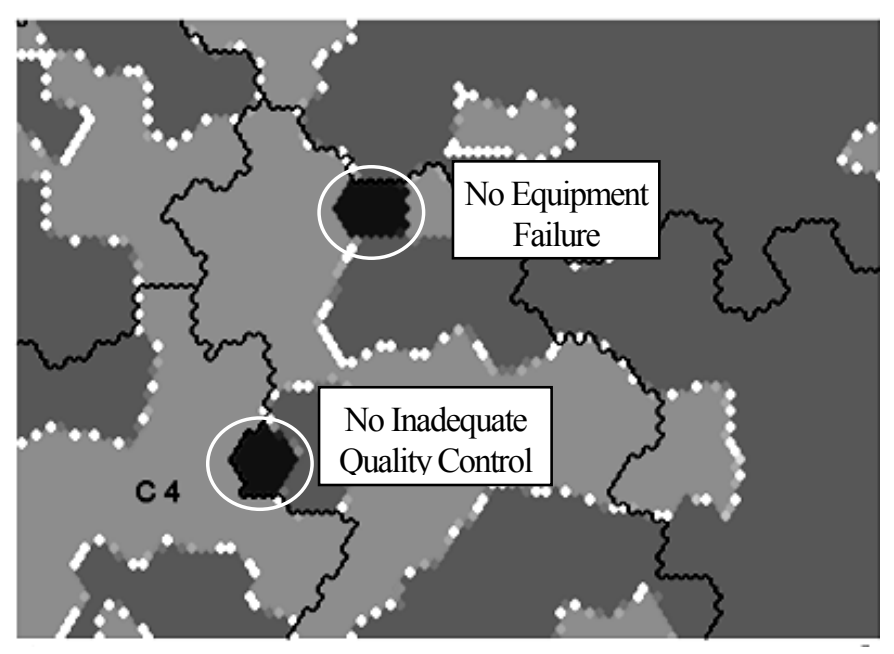

Figure 4. Insufficient Knowledge SOM

Apart from the situations where the simultaneous failure of the threesome Design-Quality ControlEquipment was present, the Wrong Type factor in cluster one only persisted in the few cases where a Wrong Reasoning cognitive function was also shown (shadowed regions on Figures 5 and 6). It means that even when one of the three main factors was not decisive, a faulty reasoning involving inferences, generalisations or deduction was still capable of leading to an erroneous action and contribute to an accident. Similarly to the Wrong Time factor, erroneous actions classified as Wrong Type also persisted when the Design Failure was not critical, but only when combined with Insufficient Skills.

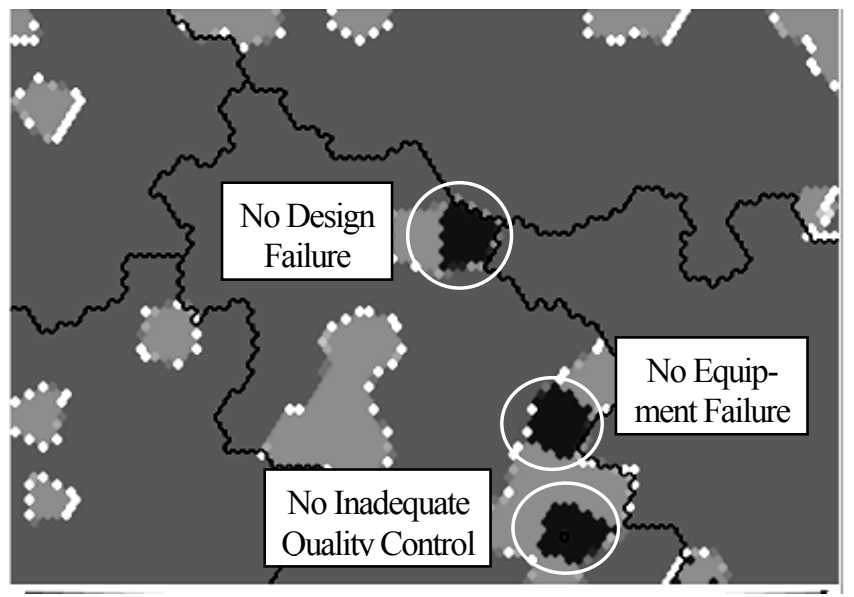

Figure 5: Wrong Type SOM

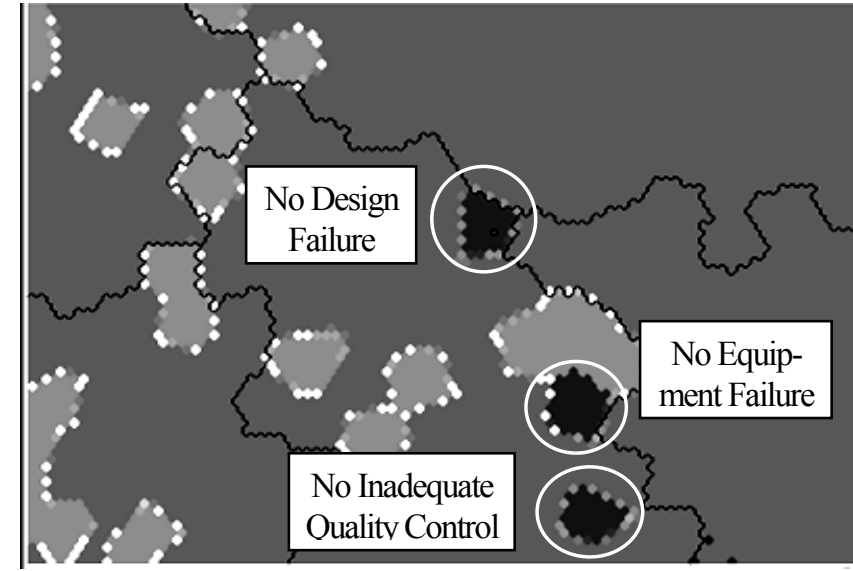

Figure 6: Wrong Reasoning SOM

In Cluster 4, accidents were largely based on the trio Design-Quality-Task Allocation, all organisational features. The manifestation of human erroneous actions was heavily determined by the Wrong Place feature, accompanied by a specific interpretation cognitive function, the Wrong Reasoning factor. Contrasting with Cluster 1, where other factors (e.g. Insufficient Skills) joined some erroneous actions to produce an accident sequence even in the absence of a design flaw, no observable single feature could substitute the Design Failure and direct link with the Wrong Place in this cluster. Additionally, $100 \%$ of the Wrong Place appearances were simultaneously influenced by Inadequate Task Allocation and Inadequate Quality Control.

Table 3 exemplifies the nature of accidents grouped in Cluster 4. Design Failures are combined with interpretation cognitive functions to stimulate a Wrong Place erroneous action type. In these cases, the number of cognitive functions associated to observation and planning was negligible.

Table 3. Cluster 4 accident examples

\begin{tabular}{cccc}
\hline Design Failure & Observation & Interpretation & Erroneous Action \\
\hline $\begin{array}{c}\text { Design of the pipe trench al- } \\
\text { lowed hot water/solids to } \\
\text { stay in permanent contact } \\
\text { with hydrogen pipe. }\end{array}$ & $\begin{array}{c}\text { A recent leak in a non-related nitro- } \\
\text { gen pipe in the plant made induced } \\
\text { operator to think that the new leakage } \\
\text { was similar. (Wrong Reasoning) }\end{array}$ & $\begin{array}{c}\text { Sequence, Jump forward: mainte- } \\
\text { nance skipped testing and continued } \\
\text { service without knowing the liquid } \\
\text { identification. (Wrong Place) }\end{array}$ \\
\hline $\begin{array}{c}\text { Operator interpreted the temperature } \\
\text { problem as a product quality issue }\end{array}$ & Wrong action: operator opened fur- \\
ature controller. & $\begin{array}{c}\text { and ignored the safety critical matter } \\
\text { of letting the furnace doors open. }\end{array}$ & $\begin{array}{c}\text { nace doors to control temperature as } \\
\text { it was too high. (Wrong Place) }\end{array}$ \\
\hline
\end{tabular}




\section{DISCUSSION}

\subsection{Genesis of human errors in major accidents}

The Design Failure feature was the most significant single contributor to major accidents, and obtained the highest frequency in the MATA-D dataset. Enhanced analysis applying the self-organisation algorithm for clustering/data mining purposes highlighted the two areas in which design failures imposed its greatest influence: Cluster 1 and Cluster 4. In spite of being composed of a complex interaction of up to 53 features, the examination of the clustering and of the self-organising maps for each individual feature indicated that the major accidents origins in these two areas seem to lie on a straightforward and narrow basis to trigger disturbances in cognitive functions. As a direct result, the manifestation of very specific human erroneous actions in the end of the accident sequence was recognised. Design Failure and Inadequate Quality Control were combined with Equipment Failure to trigger Wrong Time and Wrong place erroneous actions in Cluster 1, and with Inadequate Task Allocation to trigger the Wrong Place error mode in Cluster 4. Despite the differences between Cluster 1 and Cluster 4, the input-output connection depicted in Figure 7 is largely applicable, and thus can be depicted as a general pattern for major accidents related to design failures and human errors.

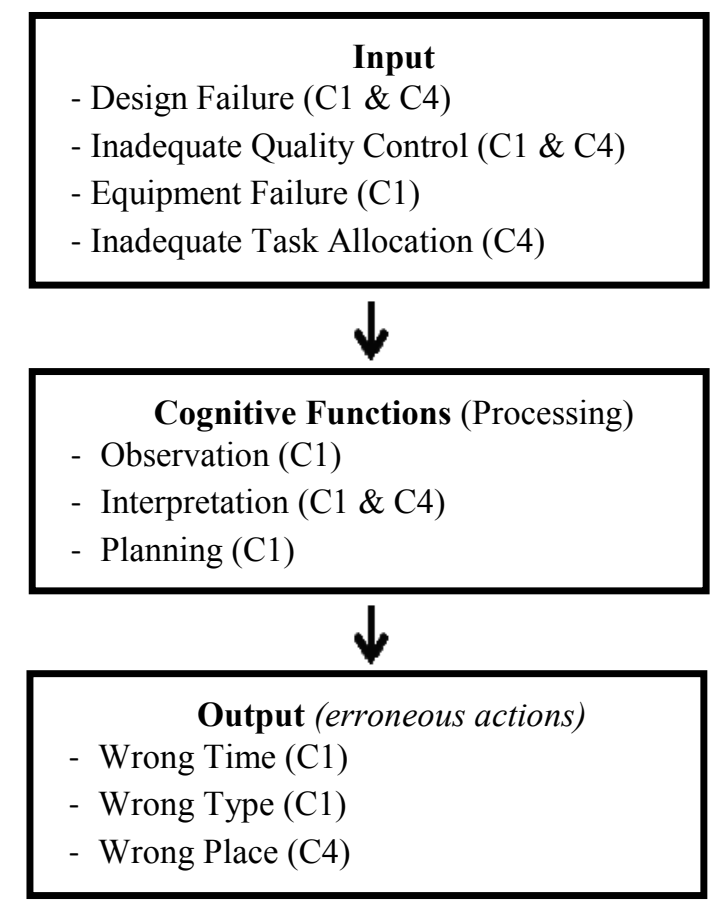

Figure 7: General configuration of human errors in industrial accidents

This model suggests that approaches which intend to prevent human error in design by simply reacting to large sets of possible human erroneous actions can be largely unsatisfactory and of limited usage, as the phenomenon focus is fundamentally wrong. Human errors can be mistakenly seen as the cause of major accidents, but the data analysis indicates that they are mainly responses to unsupportive inputs (e.g. Design Failure) which misdirected human mental processes. From a design perspective, the correct and precise approach would necessarily involve designing to support mental processes and facilitate the fluidity of the human cognitive functions.

When latent conditions embedded in design are not observable in an accident sequence, basic poor training circumstances (lack of skills) play a more significant role to contribute to accidents, but this training-related input is expected to be dealt with in future stages of the lifecycle, specifically in the operational stage. Nevertheless, as can be concluded from the Insufficient Knowledge SOM map (Figure 4) analysis, a poor design appears to override the knowledge about the system, and, to compensate the design deficiency, the human operator has to perform a complex cognition sequence, involving the observation of simultaneous clues and signals, taking immediate decisions based on interpretations and construct accurate mental plans. It is worth noticing that overlooking a cue, indication or measurement (observation missed) is particularly associated with the Wrong Time factor, as previously seen in Figures 2 and 3.

\subsection{Design transparency and comprehension}

The analysis of the results in Cluster 1 and the examples in Table 2 shows a clear path for improving design. The strong presence of the Observation Missed cognitive function exposes an issue that can be defined as "transparency of design". At first glance, errors such as starting a pump under maintenance and clamping a plate fitting upside-down can be considered to be elementary, but the broad view is that design obscurity (safety valve was located away from the equipment, design allowed an upside-down fitting and the lack of audible alarms) caused a system ambiguity difficult to interpret in the face of simultaneous operating challenges.

In Cluster 4, the design input mostly contributed to a more complex, but well-defined, flawed mental modelling. The Wrong Reasoning feature was manifested while the human operator was trying to carry out a sequence of actions (Wrong Place) to compensate (or as a consequence) of the Design Failure. Once again, an isolated analysis of the human errors such as opening the furnace doors to control temperature can appear to be inconsequential, but, in fact, an undoubtedly poor design triggered interpretation shortcomings. In these cases, the overall understanding of the system behaviour was lost. 


\section{CONCLUSIONS}

\subsection{A new two-step approach to design}

It is now clear that the early detection of latent conditions embedded in design is essential to minimise human errors and thus accidents, and the general configuration in Figure 7 aims to express a direct and useful path to support design failure prevention schemes. Significant improvement can be achieved by primarily focusing on the "transparency of design", which means to initiate the design analysis from a visibility assessment perspective - the system variables and components which are simultaneously seen by operators and serve as input to the decision-making process (largely based on cognitive functions). This study has also shown that the person in charge might perform an irregular sequence of actions to keep the system under control, and an incorrect reasoning under this environment is usually disastrous. Thus, the second step would involve the analysis of how design might support the accurate interpretation of system status and help the operator in the search for alternative solutions for operations' continuity. This would lead to a broad "comprehension of design".

Therefore, from the real-world accidents dataset scrutinised in this study, it can be concluded that designing for transparency and human comprehension can be a prevailing mechanism to transform design in the future and reduce major accidents in hightechnology industries.

\subsection{Future Developments}

Future investigation regarding the mental processes depicted in Figure 7 may perhaps give some insight into how design and organisational aspects can stimulate an improved interpretation and systemic approach to operational reality. Also, the high frequency of the quality control and maintenance failure features in Cluster 4 may deserve further examination.

A complete analysis of the MATA-D design failures description in relation to cognitive functions failures may also support the construction of a straightforward list of critical interactions to be checked during the design stage.

Existing design can benefit from the same method to scrutinise relevant factors such as training and quality control. Similarly, other clusters could be examined in the search for additional input to design improvement strategies.

The expansion of the data sample to include more high-technology accidents is also ongoing.

\section{ACKNOWLEDGEMENTS}

This study was partially funded by CAPES (Proc. $\mathrm{n}^{\mathrm{o}}$ 5959/13-6).

\section{REFERENCES}

Butler, J.E. 1980. Man-made disasters. Richmond (Victoria): Heinemann Educational

Hollnagel, E. 1998. Cognitive Reliability and Error Analysis Method. Oxford: Elsevier Science Ltd.

Kohonen, T. 2001. Self-Organizing Maps. $3^{\text {rd }}$ ed. Berlin: Springer.

Kurokawa, K. et al. 2012. The Official Report of The Fukushima Nuclear Accident Independent Investigation Commission - Executive Summary [Online] Tokyo: The National Diet of Japan. Available from: https://www.nirs.org/fukushima/naiic_report.pdf (Accessed: 6 February 2015).

Moura, R. et al. 2015a. Human error analysis: Review of past accidents and implications for improving robustness of system design, Proceedings of the $24^{\text {th }}$ European Safety and Reliability Conference, 14-18 September 2014, Wroclaw. London: Taylor \& Francis Group, pp. 10371046.

Moura, R. et al. 2015b. Learning from Accidents: Analysis and Representation of Human Errors in Multi-attribute Events. Proceedings of the 12th International Conference on Applications of Statistics and Probability in Civil Engineering, ICASP12 Vancouver, Canada, July 12-15, 2015.

Reason, J. 1990. Human Error. New York, NY: Cambridge University Press

Reason, J. 1997. Managing the Risks of Organizational Accidents. Farnham, Surrey: Ashgate Publishing Limited

Vesely, W.E. et al. 1981. NUREG-0492 - Fault Tree Handbook. Washington, DC: US Nuclear Regulatory Commission. 